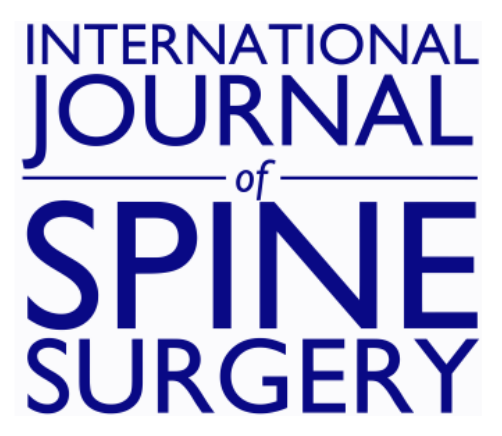

\title{
Outpatient Versus Inpatient Anterior Lumbar Spine Surgery: A Multisite, Comparative Analysis of Patient Safety Measures
}

\begin{abstract}
Jason M. Cuellar, Edward Nomoto, Ehsan Saadat, Anthony Ma, Patrick Hill, Michael Kropf, Todd H. Lanman, Brian Perri, Khawar Siddique, Willis Wagner, Rajeev Rao, Albert Wong, Michael Eng, Stephen Stephan, Neel Anand, Hyun Bae and Alexandre Rasouli
\end{abstract}

Int J Spine Surg published online 22 September 2021

http://ijssurgery.com/content/early/2021/09/20/8123

This information is current as of April 26, 2023.

Email Alerts Receive free email-alerts when new articles cite this article. Sign up at: http://ijssurgery.com/alerts 


\title{
Outpatient Versus Inpatient Anterior Lumbar Spine Surgery: A Multisite, Comparative Analysis of Patient Safety Measures
}

\author{
JASON M. CUELLAR, MD, PHD, ${ }^{1,2}$ EDWARD NOMOTO, MD ${ }^{1,2,5}$ EHSAN SAADAT, MD, ${ }^{1,2}$ \\ ANTHONY MA, ${ }^{1}$ PATRICK HILL, MD,${ }^{1,2,5}$ MICHAEL KROPF, MD ${ }^{1,2}$ TODD H. LANMAN, MD,${ }^{1,3}$ \\ BRIAN PERRI, MD,${ }^{1,2,5}$ KHAWAR SIDDIQUE, MD,${ }^{1,3,5}$ WILLIS WAGNER, MD, ${ }^{4}$ RAJEEV RAO, MD, ${ }^{4}$ \\ ALBERT WONG, MD, ${ }^{1,3,5}$ MICHAEL ENG, MD, ${ }^{2}$ STEPHEN STEPHAN, MD, ${ }^{2}$ NEEL ANAND, MD,,${ }^{1,2,5}$ \\ HYUN BAE, MD, ${ }^{1,2}$ ALEXANDRE RASOULI, MD ${ }^{1,2}$ \\ ${ }^{1}$ Cedars-Sinai Spine Center, Los Angeles, California, ${ }^{2}$ Department of Orthopaedic Surgery, Cedars-Sinai Medical Center, Los Angeles, California, ${ }^{3}$ Department of \\ Neurosurgery, Cedars-Sinai Medical Center, Los Angeles California, ${ }^{4}$ Division of Vascular Surgery, Cedars-Sinai Medical Center, Los Angeles California, \\ ${ }^{5}$ DOCS Spine + Orthopedics, Los Angeles, California
}

\begin{abstract}
Background: The frequency and complexity of spinal surgery performed in an ambulatory surgery center (ASC) is increasing. However, safety and efficacy data of most spinal procedures adapted to the ASC are sparse and have focused on anterior cervical surgery. The purpose of this study was to compare the 90-day complication and readmission rates of anterior lumbar spine surgery performed in an ASC or inpatient setting.

Methods: We performed a retrospective comparative analysis of 226 consecutive anterior lumbar surgeries (283 levels treated) completed in an ASC $(n=124)$ or in an inpatient tertiary care hospital $(n=102)$ over a 3-year period. These included anterior lumbar interbody fusion (ALIF), artificial disc replacement (ADR), and hybrids. Patients undergoing simultaneous or staged posterior procedures within 3 months were excluded. Patient demographics and surgical parameters between the two surgical settings were compared. Ninety-day medical complications and readmission rates were assessed. One-way analysis of variance and Chi-square analysis were used. A $P$ value of less than .05 was considered statistically significant.

Results: The two study groups had similar baseline characteristics. While there was a trend toward fewer complications, reoperations, and readmissions for the ASC cohort, the differences were not statistically significant. There were 7 intraoperative complications (5.6\% minor vascular injury) in the inpatient cohort and 0 in the ASC cohort. The overall 90-day postoperative complication rate was $5.6 \%$ for the inpatient cohort and $0.9 \%$ for the ASC cohort. The 90-day readmission rate was $1.9 \%$ in the ASC cohort and $1.6 \%$ in the inpatient cohort. The 90 -day reoperation rate was $0.8 \%$ for the inpatient cohort and $0 \%$ in the ASC cohort. The average hospital stay was $2.3 \pm 1.5$ days for the inpatient cohort.

Conclusion: The 90-day readmission rates were lower for outpatients than for inpatients, while the complication and reoperation rates were similar. Our results demonstrate that anterior lumbar procedures, including single-level and multilevel ALIF, ADR, and hybrid procedures, can be performed safely in an ASC. This has significant cost savings implications for the ASC setting.
\end{abstract}

Lumbar Spine

Keywords: ambulatory surgery center, ASC, inpatient, lumbar spine surgery, anterior lumbar interbody fusion, ALIF, lumbar disc replacement, ADR, hybrid

\section{INTRODUCTION}

Outpatient spinal procedures performed in ambulatory surgery centers (ASCs) are increasing in frequency in the United States. ${ }^{1,2}$ Idowu et al $^{2}$ reported that while the overall percentage of spinal surgery being performed in ASCs was still low, it increased over the 10-year period studied from 2003 to 2014. During this period, the percentage of several surgical procedures increased, most significantly for posterior lumbar decompression $(0.7$ to $10.6 \%)$, posterior lumbar fusion $(0.2$ to $2 \%)$, anterior cervical fusion ( 0 to $5 \%$ ), and posterior cervical decompression ( 0 to $23.4 \%$ ). The authors observed much greater increases for outpatient hospitals than for true free-standing $\mathrm{ASCs},{ }^{2}$ for example, from 18.7 to $68.5 \%$ for posterior lumbar decompression. Similarly, Baird et $\mathrm{al}^{3}$ reported a 
$60.5 \%$ increase ( 5.6 to $9.0 \%$ ) in outpatient cervical procedures from 2005 to 2009 in a handful of states studied. Increasing experience, proficiency, modern techniques and health care cost-saving initiatives continue to drive spine surgery toward the outpatient setting. ${ }^{4-6}$

Despite the increasing frequency of spine surgery performed in ASCs, however, there are few studies on the safety and efficacy of most spinal procedures performed in this setting. A retrospective comparison of single-level cervical artificial disc replacement (ADR) performed in ASCs versus inpatient settings revealed no difference in the rates of readmission, reoperation, or complications, ${ }^{7}$ while other reports have demonstrated lower readmission rates in the ASC cohort. $^{8-10}$ The safety of 231 single- and multilevel cervical disc replacements performed in 147 patients in an ASC setting with minimal complications or readmissions was recently reported. ${ }^{11}$

The authors are aware of only one study directly comparing the safety of anterior lumbar spine surgery performed in a free-standing ASC setting with an inpatient hospital setting, which reported on 62 patients undergoing a single-level anterior lumbar interbody fusion (ALIF) at L5-S1 in an ASC $(n=29)$ or hospital $(n=33) .{ }^{12}$ Therefore, the current study was designed to further analyze the safety of anterior lumbar spine surgery performed in the outpatient setting. This is a retrospective comparative analysis of consecutive patients that aims to quantify variables of patient demographics, complication rates, and 90-day readmission rates of anterior lumbar spinal procedures performed in both ASC and inpatient settings.

\section{METHODS}

\section{Data Collection}

Patient data were accessed through electronic medical record databases at our inpatient facility and at the collaborating ASCs. All patients in the study were treated by fellowship-trained spine surgeons. Anterior spinal exposures were performed by board-certified vascular surgeons. Patients were included if they were aged 18-80 years, had a primary lumbar ADR, ALIF, or hybrid in the last 3 years (January 1, 2016 to December 31, 2019) at one of the participating facilities, and had a minimum 90-day follow-up visit after the procedure. Patients were excluded if they had a planned associated posterior spine surgery, any recent (3 months) posterior surgery, or a history of previous anterior lumbar spine surgery. The initial query yielded 5,500 anterior lumbar procedures to be screened. After the final inclusion and exclusion criteria, the final study cohort consisted of 226 patients. Institutional review board approval was obtained.

\section{Patient Data}

Patient demographic data included sex, age, and body mass index (BMI). Comorbidity data included history of insulin-dependent diabetes mellitus, tobacco use, and history of cardiovascular diseases, including congestive heart failure, myocardial infarction, transient ischemic attack, hypertension, cardiac arrythmia, and hyperlipidemia.

\section{Intraoperative and Postoperative Parameters}

Operative parameters included the type of procedure (ALIF, ADR, or hybrid), type of facility (inpatient or ASC), surgical level(s), surgical time, anesthesia time (intubation to extubation), estimated blood loss, durotomy or vascular injury, and use of Foley catheter. Postoperative complications were monitored for 90 days after the operation and included cardiac complications, such as cardiac arrest and myocardial infarction, deep vein thrombosis, epidural hematoma, intractable pain, mortality, new onset neurological deficits, pulmonary embolism, pneumonia, pneumothorax, respiratory failure, surgical site infection, urinary retention, urinary tract infection, and vascular injury requiring repair. Discharge location (home versus inpatient rehab or after care facility) and length of hospital stay were recorded. Both reoperation and readmission within 90 days for reasons related to the surgery were recorded.

\section{Anterior Spine Exposure Surgical Technique}

The anterior spine exposure technique has been recently described in detail. ${ }^{13} \mathrm{~A}$ cell-saver blood recirculation system was available for all procedures and was on standby for the L5-S1 level and was actually used for all procedures involving levels above L5-S1. The same vascular surgeons performed the anterior access for both the inpatient and ASC patients. There were no revision anterior operations performed in this series.

\section{Anesthesia}

Anesthesia was provided to the patients in the ASC cohort by either a board-certified anesthesiol- 
ogist or by a certified registered nurse anesthetist that was highly experienced in outpatient spine surgery. A preoperative or postoperative ultrasound-guided local anesthetic injection (transversus abdominis plane block) using a long-acting agent, such as Marcaine and/or bupivacaine liposomal injectable suspension, was routinely given before incision or at the end of the operation after closure. Patients were monitored in the recovery room by the nursing and certified registered nurse anesthetist staff for an average of 3 hours. Patients were required to be ambulatory with pain controlled, be able to void, and be able to tolerate per os intake prior to discharge. Mechanical deep vein thrombosis prophylaxis was used during the intraoperative and postoperative recovery room period. No chemical anticoagulation was used. ${ }^{13}$

For the inpatient cohort, anesthesia was provided by board-certified anesthesiologists and anesthesia residents under supervision in a similar manner as to that described for the ASC cohort above, with the exception that liposomal bupivacaine was not available. In addition, an arterial line was usually placed in the inpatient setting.

\section{Statistical Analysis}

Baseline characteristics and complication data were analyzed using one-factor analysis of variance to assess differences between baseline characteristics, anesthetic duration, operative time, and length of stay (in hours) between the inpatient and ASC cohorts. Chi-square analysis was used to compare the proportion of patients in each group that underwent a one-, two-, or three-level procedure, the proportion of patients that sustained an intraoperative or postoperative complication or readmission, and the proportion of patients in each group discharged to home versus an after care facility. A $P$ value of less than .05 was considered statistically significant. AcaStat software (Winter Garden, FL) was used.

\section{RESULTS}

A total of 226 patients undergoing ALIF and ADR procedures were reviewed. The average patient age was 44 years. The mean BMI was 27.1 $\pm 5 \mathrm{~kg} / \mathrm{m}^{2}$ (range 16-44). The study cohort included $46 \%$ females. This cohort contained 124 inpatients and 102 outpatients.
Table 1. Demographic information for patients undergoing outpatient or inpatient anterior lumbar procedures.

\begin{tabular}{lccc}
\hline Characteristic & Outpatient & Inpatient & $\boldsymbol{P}$ Value \\
\hline $\begin{array}{l}\text { Number of patients } \\
\text { \% Female }\end{array}$ & 102 & 124 & $>.05$ \\
$\begin{array}{l}\text { Age, mean } \pm \mathrm{SD}, \mathrm{y} \\
\text { Body mass index, }\end{array}$ & 48.0 & 45.2 & $>.05$ \\
$\quad$ mean \pm SD, kg/m & $26.6 \pm 11.9$ & $47.6 \pm 12.7$ & $>.05$ \\
$\begin{array}{l}\text { Smokers: current; former } \\
\text { Diabetes requiring glucose } \\
\quad \text { control with insulin }\end{array}$ & $7 ; 8$ & $27.3 \pm 5.7$ & $>.05$ \\
$\begin{array}{l}\text { Known history of } \\
\text { cardiovascular disease }\end{array}$ & 0 & $6 ; 26$ & $>.05$ \\
\hline
\end{tabular}

Abbreviations: SD, standard deviation.

For inpatients, the average age was $48 \pm 13$ years. The mean BMI was $27 \pm 4 \mathrm{~kg} / \mathrm{m}^{2}$ (range 1644). The inpatient cohort included 56 females and 68 males. Patient comorbidities included 6 patients who were current smokers, 26 former smokers, 1 with type 2 diabetes, and 23 with a history of cardiovascular disease.

The ASC cohort included 49 females and 53 males, with an average age of $43 \pm 12$ years. The mean BMI was $27 \pm 4 \mathrm{~kg} / \mathrm{m}^{2}$ (range 18-37). Seven patients were current smokers, 8 were former smokers, none had insulin-dependent diabetes, and 15 had a history of cardiovascular disease. None of these baseline characteristics were statistically significantly different between the 2 cohorts (Table 1 ).

A total of 283 levels were operated on for the 226 patients included in the study. Of the total number of operative levels, 51 were combined two- and three-level ALIF/ADR procedures, and 172 were single-level cases (Table 2).

For the inpatient cohort, a total of 167 levels were operated on in 124 procedures and were divided into 83 single-level, 39 two-level, and 2 three-level (including hybrid) procedures. Surgeries were calculated as 51 ALIF, 56 ADR, and 17 hybrid procedures. The average surgery time was $117.1 \pm$ 37 minutes, and the average anesthesia time was 191 \pm 52 minutes. The average estimated blood loss was $110 \pm 126 \mathrm{~mL}$.

For the outpatient cohort, a total of 116 levels were operated on in 102 procedures and were divided into 89 single-level, 12 two-level, and 1 three-level (including hybrid) procedures. Surgeries were calculated as $42 \mathrm{ALIF}, 60 \mathrm{ADR}$, and 3 hybrid procedures. There were significantly more two-level procedures in the inpatient group $(P<.01)$. The average surgery time was $98 \pm 24$ minutes, and average anesthesia time was $149 \pm 50$ minutes. The average EBL was $65 \pm 63 \mathrm{~mL}$. Mean surgery and 
Table 2. Surgical parameters.

\begin{tabular}{|c|c|c|c|}
\hline & Outpatient & Inpatient & $P$ Value \\
\hline Patients treated & 102 & 124 & \\
\hline \multicolumn{4}{|l|}{ Levels treated } \\
\hline Total & 116 & 167 & $>.05$ \\
\hline L5-S1 & 73 & 88 & $>.05$ \\
\hline L4-5 & 32 & 66 & $>.05$ \\
\hline L3-4 & 7 & 11 & $>.05$ \\
\hline L2-3 & 0 & 2 & $>.05$ \\
\hline Single-level & 89 & 83 & $>.05$ \\
\hline Two-level & 12 & 39 & $<.01$ \\
\hline Three-level & 1 & 2 & $>.05$ \\
\hline ADR & 60 & 56 & $>.05$ \\
\hline ALIF & 39 & 51 & $>.05$ \\
\hline Hybrid ADR/ALIF & 3 & 17 & $>.05$ \\
\hline $\begin{array}{l}\text { Total surgery time, } \\
\text { mean } \pm \mathrm{SD}, \text { min }\end{array}$ & $97.7 \pm 24.4$ & $117.1 \pm 37.5$ & $<.01$ \\
\hline $\begin{array}{l}\text { Total anesthesia time, } \\
\text { mean } \pm \mathrm{SD}, \text { min }\end{array}$ & $148.6 \pm 49.9$ & $190.6 \pm 52.4$ & $<.001$ \\
\hline $\begin{array}{l}\text { Estimated blood loss, } \\
\text { mean } \pm \mathrm{SD}, \mathrm{mL}\end{array}$ & $64.8 \pm 62.6$ & $108.9 \pm 126.3$ & $<.01$ \\
\hline Intraoperative complication & 0 & 7 (vein injury) & $>.05$ \\
\hline \multicolumn{4}{|l|}{$\begin{array}{l}\text { Postoperative complication } \\
\text { observed ( } 90 \text { days) }\end{array}$} \\
\hline Total, $n(\%)$ & $1(0.9)$ & $7(5.6)$ & $>.05$ \\
\hline DVT & 1 & 0 & \\
\hline SSI & 0 & 1 & \\
\hline UTI & 0 & 1 & \\
\hline Ileus & 0 & 0 & \\
\hline Urinary retention & 0 & 3 & \\
\hline Reoperations & 0 & 2 & \\
\hline Average length of stay, $h$ & 5.2 & 56.9 & $<.001$ \\
\hline $\begin{array}{l}\text { Reoperation rate (90 days), } \\
n(\%)\end{array}$ & $0(0.0)$ & $1(0.8)$ & $>.05$ \\
\hline $\begin{array}{l}\text { Unplanned hospital readmission } \\
\text { (90 days), } n(\%)\end{array}$ & $2(1.9)$ & $2(1.6)$ & $>.05$ \\
\hline Discharged directly home & 83 & 122 & $<.001$ \\
\hline Discharged to after care facility & 19 & 2 & $<.001$ \\
\hline
\end{tabular}

Abbreviations: ADR, artificial disc replacement; ALIF, anterior lumbar interbody fusion; DVT, deep vein thrombosis; SD, standard deviation; SSI, surgical site infection; UTI, urinary tract infection.

anesthesia times were both significantly less in the ASC group than in the inpatient group $(P<.005$ and $P<.0001$, respectively).

Overall, the 90-day postoperative complication rates in both the inpatient and ASC cohorts was low, $5.6 \%$ and $0.9 \%$, respectively. The most common complication was minor vascular injury to the iliac vein $(3 \%)$, urinary retention $(1.3 \%)$, ileus $(0.4 \%)$, deep vein thrombosis $(0.4 \%)$, and surgical site infection $(0.4 \%)$.

When comparing complication rates of the inpatient and ASC cohorts, there were no statistical differences in the rate of complications. The overall inpatient complication rate was $(5.6 \%)$. There were no mortalities. There were no statistically significant differences between the 2 groups.

For the inpatient cohort, there was 1 reoperation $(0.8 \%)$ and 2 readmissions $(1.6 \%)$. One unplanned readmission was on postoperative day (POD) 6 for a 56-year-old patient with peri-incisional swelling and pain, fatigue, and dizziness post ADR at L2-3 and L3-4. The patient was diagnosed with a surgical site infection and extraperitoneal hematoma, was treated with antibiotics, and was discharged home on hospital day 2. The second readmission was a 36year-old male patient who was a current smoker with a BMI of 25 and no other past medical history who had undergone an L4-S1 hybrid without complications and was discharged on hospital day 4. The patient was readmitted on POD 7 for sepsis secondary to pneumonia and was treated with antibiotics and discharged to home on hospital day 2. The only unplanned reoperation within 90 days was a revision decompression at L4-5 and L5S1 on POD 76 for persistent radicular pain in a 36year-old diabetic male with a BMI of 21 who had undergone an uncomplicated L5-S1 ADR and was discharged on POD 2.

For the ASC cohort, there were 0 reoperations and $2(1.6 \%)$ hospital readmissions within 90 days. This was not statistically significantly different compared with the hospital cohort. The first was a 30 -year-old male with no significant past medical history and a BMI of 25.8 admitted with a complaint of abdominal pain on POD 1 after an uncomplicated ADR at L5-S1. The patient was monitored, found to have stable laboratory blood values and vital signs, and was therefore discharged to home without additional imaging or work-up after a one-night hospital stay and improved pain. The second patient was a 40-year-old female smoker without other known medical comorbidities (BMI of 21.8) who underwent an uncomplicated L4-S1 ADR. On POD 17 she was admitted to a hospital with a rash on her neck and face and a low-grade fever. Infectious disease initially treated her with ceftriaxone for presumed cellulitis. She was then diagnosed with contact dermatitis and discharged home on hospital day 4 without further sequelae.

The average inpatient hospital stay was $2.3 \pm 1.5$ days. There were significantly more patients treated in the hospital setting discharged to home $(98.4 \%$, 122/124 inpatients) than ASC patients $(78.4 \%, 80 /$ 102 ASC $)(P<.001)$ because 19 patients in the ASC group were sent to a short-term after care facility to avoid a prolonged drive home on the day of surgery. The patients that did go to an after care facility stayed there 1 night on average before going home. No patient stayed overnight at the ASC or was admitted to the hospital. 


\section{DISCUSSION}

Spine surgery in ASCs has been increasingly used, providing a more cost-efficient alternative to a hospital setting. ${ }^{4,14}$ As cost reduction efforts continue to influence surgical care, it is reasonable to anticipate a progressive increase in the percentage of spine surgery being performed in ASCs. While there is a limited but growing body of literature in support of the push to expand the ASC spine surgical indications, ${ }^{5}$ few of these studies have directly compared inpatient with ASC cohorts.

Several studies have compared ASC anterior cervical fusion or disc replacement with inpatient cohorts. ${ }^{8-10,14-20}$ While there are also numerous reports on the safety of ASC posterior, ${ }^{21-26}$ anterior, ${ }^{13}$ and lateral lumbar spinal surgery, ${ }^{27,28}$ there are very few ASC inpatient comparison studies for lumbar spine surgery. Emami and colleagues compared inpatient and ASC single- and two-level minimally invasive surgical transforaminal lumbar interbody fusion procedures, reporting similar outcomes with a slightly lower readmission rate for the ASC cohort. ${ }^{29}$ Villavicencio and colleagues also compared ASC and inpatient transforaminal lumbar interbody fusion complication rates, reporting a numerically greater but statistically similar rate for both cohorts. ${ }^{26}$ Chin and colleagues compared 30 patients undergoing lateral lumbar interbody fusions in an ASC to 40 patients undergoing surgery in a hospital setting. ${ }^{28}$ The authors observed fewer complications $(7 \%$ versus $20 \%$ ), reduced estimated blood loss, shorter surgery times, and superior 2-year outcomes in the ASC group compared with the inpatient group.

Data on the comparison of complication rates between inpatient and ASC anterior lumbar procedures is even more sparse, with only one relatively small study to date that we are aware of; Snowden et $\mathrm{al}^{12}$ reported their findings on 62 patients undergoing single-level ALIF at L5-S1 in the ASC $(n=29)$ or inpatient $(n=33)$ setting. The authors reported a postoperative complication rate of $10.3 \%$ in the ASC group versus $15.1 \%$ in the hospital group, with no significant difference between the groups. Hospital readmissions were not reported.

In the present study we evaluated the complication rates of 226 consecutive patients undergoing ALIF, ADR, or hybrid procedures performed either in an inpatient or an ASC setting for both singleand multilevel L2-S1 procedures. Surprisingly, it was observed that the two cohorts were very similar at baseline regarding BMI and medical comorbidities, contrary to our expectation that the inpatient cohort would have a much greater BMI and medical comorbidity rate. The inpatient cohort was slightly older on average and was more likely to have undergone a multilevel procedure, both of which were expected findings. The greater number of multilevel (and upper-lumbar-level) procedures in the inpatient cohort probably contributed to the increased number of vascular injuries experienced in this cohort as well as the longer surgical times and greater estimated blood loss. The 7 patients with vascular injuries $(5.6 \%)$ had an average BMI of 26.8 $\mathrm{kg} / \mathrm{m}^{2}$ (range 23-28), an age range of 33-56 years, and had undergone the following procedures: twolevel hybrids at L4-5 and L5-S1 $(n=4)$, two-level ADR at L4-5 and L5-S1 $(n=1)$, and single-level ADR at L4-5 $(n=2)$. All vascular injuries were minor vein injuries that were repaired with suture without significant sequelae.

There were also more postoperative complications observed in the inpatient cohort $(5.6 \%$ versus $0.9 \%$ ), which included 1 surgical site infection, 1 urinary tract infection, 1 case of ileus, 3 cases of urinary retention, and 2 reoperations within 90 days. These mostly medical-related postoperative complications in the inpatient cohort are also likely explained by the slightly older cohort (48 versus 43 years old on average) undergoing, on average, a greater number of levels: 41 two- and three-level procedures versus only 13 in the ASC cohort. Overall the intraoperative and postoperative complication rate was within the range of prior literature. ${ }^{30}$ For example, Aghayev and colleagues ${ }^{30}$ reported that of 248 patients treated with multilevel ADR (L2-S1), there were 11 intraoperative complications $(4.4 \%)$ that included 5 vascular injuries. These occurred more often during two-level ADR (7.1\%) than during one-level ADR (3.6\%). ${ }^{30}$ They observed a reoperation rate of $4.4 \%$ over 5 years, with average time to first revision being 33 months. Rasouli and colleagues ${ }^{31}$ reported outcomes after two-, three-, and four-level lumbar ADR in 159 patients, observing 3 reoperations. There were 4 cases of new radiculopathy that resolved within 6 weeks, 4 cases of lower extremity deep vein thrombosis, and no pulmonary embolism. There was 1 surgical site infection. ${ }^{31}$

This study observed only 2 unplanned hospital readmissions $(1.9 \%)$ in the ASC cohort and 2 
$(1.6 \%)$ in the inpatient cohort, and this was not a statistically significant difference.

The length of stay in the present study was 57 hours (2.4 days) compared with the average ASC stay of 5.2 hours. This will have significant costsavings implications if more of these surgical procedures can be performed in an ASC with a similar safety profile. While we did not currently study the cost, it has been demonstrated to be far less in an ASC, ${ }^{19,32}$ with overall charges less than $50 \%$ of the cost for the same procedure performed in an inpatient setting. ${ }^{14,32}$ Therefore, these results may imply that lumbar spine surgery in an ASC may deliver increased value compared with similar procedures performed in the hospital setting.

Of primary concern when performing anterior lumbar spine surgery is patient safety, regardless of the setting. This concern has perhaps caused many spine surgeons to be hesitant to perform these types of operations in ASCs. We believe prevention of complications rests primarily on the experience of the vascular access surgeon and spine surgeon and patient selection. For patient selection, body habitus is very important; patients with centripetal obesity are at both greater risk for sustaining a vascular injury and difficulty of vascular repair. If a patient sustains a significant vascular injury, a system must be in place to manage this occurrence. At the ASC, it is imperative to have a cell-saver system in use to capture lost blood and transfuse the patient. The primary management strategies lacking at the ASC include the ability for allogenic blood transfusion and advanced imaging/interventional radiology. Therefore, a protocol for rapid transfer to a nearby tertiary care hospital must be in place in the instance that this becomes necessary.

There are several limitations to this study. While this is a relatively large cohort of patients, it may still be underpowered to find a statistically significant difference in the rate of uncommon complications between 2 cohorts of patients. Furthermore, while the 2 cohorts were relatively well matched regarding sex and age, the inpatient cohort contained a greater number of multilevel and upperlumbar-level procedures. This will inherently bias this group towards greater complications. There is also an inherent bias in patient selection for the ASC versus the hospital.

Another limitation of this study is the lack of patient-reported outcomes. The outcomes of lumbar disc replacement, ${ }^{33-35}$ including multilevel ${ }^{31,36}$ or stand-alone ALIF, ${ }^{37,38}$ have been reported by many other authors and was not the aim of the current study, which focuses on evaluating the safety of these procedures performed in an ASC compared with in a hospital setting.

The reproducibility of these results depends heavily on the availability of a highly experienced vascular access surgeon. The 2 vascular surgeons used by our group have each performed several thousand anterior lumbar access operations over their careers, including hundreds in an ASC setting. In addition, the anesthesia providers for both cohorts are highly experienced in providing anesthesia for spinal surgery procedures.

In conclusion, there was an overall low intraoperative and 90-day postoperative complication rate and no statistically significant difference between the inpatient and ASC cohorts treated by anterior lumbar procedures, including single and multilevel ALIF and ADR in 226 patients (283 levels). In addition, reoperation and readmission rates were not statistically different between the 2 groups. These results support that anterior lumbar surgery can be safely performed in an ASC setting with an experienced vascular surgeon and spine surgeon team exercising cautious patient selection. While cost was not directly studied, these results may suggest a significant cost savings and thus improved value of anterior lumbar spine surgery performed in an ASC compared with a hospital setting.

\section{REFERENCES}

1. Ahn J, Bohl DD, Tabaraee E, Basques BA, Singh K. Current trends in outpatient spine surgery. Clin Spine Surg 2016;29(9):384-386.

2. Idowu OA, Boyajian HH, Ramos E, Shi LL, Lee MJ. Trend of spine surgeries in the outpatient hospital setting versus ambulatory surgical center. Spine (Phila Pa 1976) 2017;42(24):E1429-E1436.

3. Baird EO, Egorova NN, McAnany SJ, Quershi SA, Hecht AC, Cho SK. National trends in outpatient surgical treatment of degenerative cervical spine disease. Global Spine $J$ 2014;4(3):143-150.

4. Mundell BF, Gates MJ, Kerezoudis P, et al. Does patient selection account for the perceived cost savings in outpatient spine surgery? A meta-analysis of current evidence and analysis from an administrative database. $J$ Neurosurg Spine 2018;29(6):687-695.

5. Sivaganesan A, Hirsch B, Phillips FM, McGirt MJ. Spine surgery in the ambulatory surgery center setting: value-based advancement or safety liability? Neurosurgery 2018;83(2):159165.

6. Gologorsky Y. Outpatient spine surgery: transition to the ambulatory surgery center. World Neurosurg 2018;114:369-370. 
7. Segal DN, Wilson JM, Staley C, Yoon ST. Outpatient and inpatient single-level cervical total disc replacement: a comparison of 30-day outcomes. Spine (Phila Pa 1976) 2019;44(1):7983.

8. Khalid SI, Kelly R, Wu R, Peta A, Carlton A, Adogwa O. A comparison of readmission and complication rates and charges of inpatient and outpatient multiple-level anterior cervical discectomy and fusion surgeries in the Medicare population. J Neurosurg Spine 2019:1-7. doi:10.3171/2019.3. SPINE181257

9. Khalid SI, Kelly R, Carlton A, et al. Outpatient and inpatient readmission rates of 3- and 4-level anterior cervical discectomy and fusion surgeries. $J$ Neurosurg Spine 2019:31(1):70-75.

10. Khalid SI, Carlton A, Wu R, Kelly R, Peta A, Adogwa O. Outpatient and inpatient readmission rates of 1- and 2-level anterior cervical discectomy and fusion surgeries. World Neurosurg 2019;126:e1475-e1481.

11. Cuellar JM, Lanman TH, Rasouli A. The safety of single and multi-level cervical total disc replacement in ambulatory surgery centers. Spine (Phila Pa 1976) 2019;45:512-521.

12. Snowden R, Fischer D, Kraemer P. Early outcomes and safety of outpatient (surgery center) vs inpatient based L5-S1 anterior lumbar interbody fusion. J Clin Neurosci 2020;73:183186.

13. Cuellar JM, Wagner W, Rasouli A. Low complication rate of anterior lumbar spine surgery in an ambulatory surgery center. Int J Spine Surg 2020;14(5)In press. doi:10. $14444 / 7100$

14. Purger DA, Pendharkar AV, Ho AL, et al. Outpatient vs inpatient anterior cervical discectomy and fusion: a populationlevel analysis of outcomes and cost. Neurosurgery 2018;82(4):454-464.

15. Adamson T, Godil SS, Mehrlich M, Mendenhall S, Asher AL, McGirt MJ. Anterior cervical discectomy and fusion in the outpatient ambulatory surgery setting compared with the inpatient hospital setting: analysis of 1000 consecutive cases. $J$ Neurosurg Spine 2016;24(6):878-884.

16. Liu JT, Briner RP, Friedman JA. Comparison of inpatient vs. outpatient anterior cervical discectomy and fusion: a retrospective case series. BMC Surg 2009;9:3. doi:10.1186/ 1471-2482-9-3

17. Khanna R, Kim RB, Lam SK, Cybulski GR, Smith ZA, Dahdaleh NS. Comparing short-term complications of inpatient versus outpatient single-level anterior cervical discectomy and fusion: an analysis of 6940 patients using the ACS-NSQIP database. Clin Spine Surg 2018;31(1):43-47.

18. McClelland S III, Passias PG, Errico TJ, Bess RS, Protopsaltis TS. Inpatient versus outpatient anterior cervical discectomy and fusion: a perioperative complication analysis of 259,414 patients from the healthcare cost and utilization project databases. Int J Spine Surg 2017;11(2):11. doi:10. $14444 / 4011$

19. Purger DA, Pendharkar AV, Ho AL, et al. Analysis of outcomes and cost of inpatient and ambulatory anterior cervical disk replacement using a state-level database. Clin Spine Surg 2019;32(8):E372-E379.

20. Wohns R. Safety and cost-effectiveness of outpatient cervical disc arthroplasty. Surg Neurol Int 2010;1:77. doi:10. 4103/2152-7806.73803

21. Best NM, Sasso RC. Outpatient lumbar spine decom- pression in 233 patients 65 years of age or older. Spine (Phila Pa 1976) 2007;32(10):1135-1139; discussion 1140.

22. Best NM, Sasso RC. Success and safety in outpatient microlumbar discectomy. J Spinal Disord Tech 2006;19(5):334337.

23. An HS, Simpson JM, Stein R. Outpatient laminotomy and discectomy. J Spinal Disord 1999;12(3):192-196.

24. Singhal A, Bernstein M. Outpatient lumbar microdiscectomy: a prospective study in 122 patients. Can J Neurol Sci 2002;29(3):249-252.

25. Helseth O, Lied B, Halvorsen CM, Ekseth K, Helseth E. Outpatient cervical and lumbar spine surgery is feasible and safe: a consecutive single center series of 1449 patients. Neurosurgery 2015;76(6):728-737; discussion 737-738.

26. Villavicencio AT, Nelson EL, Mason A, Rajpal S, Burneikiene S. Preliminary results on feasibility of outpatient instrumented transforaminal lumbar interbody fusion. J Spinal Disord Tech 2013;26(6):298-304.

27. Smith WD, Wohns RN, Christian G, Rodgers EJ, Rodgers WB. Outpatient minimally invasive lumbar interbody: fusion predictive factors and clinical results. Spine (Phila Pa 1976) 2016;41(s8):S106-S122.

28. Chin KR, Pencle FJ, Coombs AV, et al. Lateral lumbar interbody fusion in ambulatory surgery centers: patient selection and outcome measures compared with an inhospital cohort. Spine (Phila Pa 1976) 2016;41(8):686-692.

29. Emami A, Faloon M, Issa K, et al. Minimally invasive transforaminal lumbar interbody fusion in the outpatient setting. Orthopedics 2016;39(6):e1218-e1222.

30. Aghayev E, Etter C, Barlocher C, et al. Five-year results of lumbar disc prostheses in the SWISSspine registry. Eur Spine $J$ 2014;23(10):2114-2126.

31. Rasouli A, Cuellar JM, Kanim L, et al. Multiple-level lumbar total disk replacement: a prospective clinical and radiographic analysis of motion preservation at 24-72 months. Clin Spine Surg 2019;32(1):38-42.

32. Bekelis K, Missios S, Kakoulides G, Rahmani R, Simmons N. Selection of patients for ambulatory lumbar discectomy: results from four US states. Spine $J$ 2014;14(9):1944-1950.

33. Zigler JE, Delamarter RB. Five-year results of the prospective, randomized, multicenter, Food and Drug Administration investigational device exemption study of the ProDisc$\mathrm{L}$ total disc replacement versus circumferential arthrodesis for the treatment of single-level degenerative disc disease. $J$ Neurosurg Spine 2012;17(6):493-501.

34. Yue JJ, Garcia R, Blumenthal S, et al. Five-year results of a randomized controlled trial for lumbar artificial discs in single-level degenerative disc disease. Spine (Phila Pa 1976) 2019;44(24):1685-1696.

35. Jacobs W, Van der Gaag NA, Tuschel A, et al. Total disc replacement for chronic back pain in the presence of disc degeneration. Cochrane Database Syst Rev 2012;(9):CD008326. doi:10.1002/14651858.CD008326.pub2

36. Zigler JE, Ohnmeiss DD. Comparison of 2-level versus 1-level total disc replacement: results from a prospective FDAregulated trial. $S A S J$ 2008;2(3):140-144.

37. Norotte G, Barrios C. Clinical and radiological outcomes after stand-alone ALIF for single L5-S1 degenerative discopathy using a PEEK cage filled with hydroxyapatite nanoparticles without bone graft. Clin Neurol Neurosurg 2018;168:24-29. 
38. Udby PM, Bech-Azeddine R. Clinical outcome of standalone ALIF compared to posterior instrumentation for degenerative disc disease: a pilot study and a literature review. Clin Neurol Neurosurg 2015;133:64-69.

Disclosures and COI: The authors have no relevant financial disclosures.

Corresponding Author: Jason M. Cuellar, $\mathrm{MD}, \mathrm{PhD}, 450 \mathrm{~N}$ Roxbury Drive, 3rd Floor,
Beverly Hills, CA 90210. Phone: (310)-385-7766 (office); Email: cuellarj@gmail.com.

Published 0 Month 2021

This manuscript is generously published free of charge by ISASS, the International Society for the Advancement of Spine Surgery. Copyright (C) 2021 ISASS. To see more or order reprints or permissions, see http://ijssurgery.com. 